\title{
The Risk Factors of Premature Myocardial Infarction: A Case Control Study in Iran
}

\author{
Mehdi Ehtesham ${ }^{1}$, Ali Akbar Haghdoost ${ }^{2}$, Seyed Vahid Ahmadi Tabatabaei ${ }^{3} \&$ Hooman Bakhshandeh ${ }^{4}$ \\ ${ }^{1}$ Avicenna Research Consulting, London, United Kingdom \\ ${ }^{2}$ Research Centre for Modelling in Health, Institute for Futures Studies in Health, Kerman University of Medical \\ Sciences, Kerman, Iran \\ ${ }^{3}$ Department of Health Education and Promotion, School of Public Health, Tehran University of Medical \\ Sciences, Tehran, Iran \\ ${ }^{4}$ Rajaie Cardiovascular Medical and Research Centre, Iran University of Medical Sciences, Tehran, Iran \\ Correspondence: Prof. Ali Akbar Haghdoost, Research Center for Modeling in Health, Institute for Futures \\ Studies in Health, Kerman University of Medical Sciences, Kerman, Iran. Tel: 98-341-210-5801. E-mail: \\ ahaghdoost@kmu.ac.ir
}

Received: October 13, 2015 Accepted: February 17, 2016 Online Published: February 29, 2016

doi:10.5539/gjhs.v8n11p69 URL: http://dx.doi.org/10.5539/gjhs.v8n11p69

\begin{abstract}
Background: Although, our knowledge about the factors of cardio vascular diseases (CVD) is relatively acceptable, we have few publications about the risk factors of premature CVD particularly from developing
\end{abstract} countries such as Iran.

Objectives: The present study is aimed to assess the risk of the modifiable risk factors of coronary heart disease (CHD) in the first cardiac attack of patients classified by age to check which risk factors might have a more significant impact to increase the risk of premature myocardial infarction (MI).

Methods: In a case control study, 122 and 266 cases and controls were recruited from one of the main referral centres in Tehran. Cases were those who were hospitalized because of their first myocardial infarction before the ages of 50 and 55 years in males and females respectively, and compared their risk factor profiles with those experienced first MI in higher age. Main independent variables in this study were: the demographic variables, distress, lipid profile, diabetes, smoking, family history of cardio vascular diseases, and physical activity.

Results: The results showed that distress $(\mathrm{OR}=3.95)$, minorities (compare to Fars race) $(\mathrm{OR}=3.30)$, higher education $(\mathrm{OR}=1.30)$, family history of hyperlipidaemia $(\mathrm{OR}=1.89)$ significantly increased the risk of premature MI. We also found that family history of hypertension $(\mathrm{OR}=1.35)$, current smoking versus no smoking $(\mathrm{OR}=1.60)$, fast-food consumption $(\mathrm{OR}=1.48)$, non-alcoholic beverages $(\mathrm{OR}=1.12)$ had also association with the risk of premature MI but only in crude model. We also found that regular physical activity $(\mathrm{OR}=0.42)$, ex-smoker versus current smoking $(\mathrm{OR}=0.27)$ and regular consumption of milk $(\mathrm{OR}=0.73)$ was protective against premature MI.

Conclusion: Our findings demonstrate that the effect of most of risk factors were mostly related to their life-style (distress, smoking, physical inactivity and dietary pattern); while family history of diseases was also important.

Keywords: case-control study, premature myocardial infarction, risk-factors of CVD, cardio vascular disease

\section{Introduction}

\subsection{Introduce the Problem}

According to World Health Organization (WHO) report, non-communicable diseases are the reason for $50 \%$ of the deaths in the developing countries and it is expected to rise to $70 \%$ by 2020 . (WHO, 2004). WHO also reports that around 16 million individuals suffer from CVD in the world and this shift is growing in developing countries dramatically (WHO, 2002).

Several studies had conducted researches for premature MI in the world, and each region highlighted a different 
priority of risk factors for premature MI (Avies et al., 2012). Joshi et al. (2007) concluded that low level of socio-economic status (SES) was the main risk factor for premature MI among natives of the South Asian countries. Additionally, their results showed that the South Asian countries had the highest prevalence rate of premature MI, in comparison to the other parts of the world. Results gathered from another study have demonstrated that smoking and drug abuse are the greatest risk of premature MI in Spain (Andrés et al., 2011).

\subsection{Explore Importance of the Problem}

In Iran, the significant issue is the dramatically changing life-style. Same as many other developing countries, Iran is becoming industrialized; therefore side-effects of health transition might be forecasted (Azizi, Janghorbani, \& Hatami, 2000). Iran also needs to deal with new phenomenon; i.e. sedentary life-style, the increase of fatty and fast food consumption and incidence rate of smoking and drug abuse. All of these habits can be introduced as risk-factors of CVD, therefore health programmers and policy makers need more data about these hazards (Meysamie et al., 2010).

In this relation, the results of a study have revealed that, fibrinogen had increased the risk premature MI in Iran (Buttar \& Ravi, 2005). Kazemi et al. (2011) had mentioned that family history of coronary artery diseases (CAD), smoking, diabetes and dyslipidaemia significantly increased the risk of premature MI in small city, Iran.

\subsection{Objectives}

To compare the pattern of known CHD risk factors in the first cardiac attacked of patients classified by age to check which risk factors might have more significant impact to increase the risk of premature MI.

\section{Methods}

\subsection{Participants}

Out of approximately 500 candidates in total, 388 candidates had signed the ethical committee forms which were approved by Rajaie Cardiovascular Medical and Research Centre, Tehran, the main tertiary care centre for cardiovascular patients in Iran; finally 122 cases and 266 controls were enrolled between June 2012 and July 2013.

Methods of diagnosis and categorizing the groups: "Among the diagnostic tests available to detect heart muscle damage were an electrocardiogram (ECG), echocardiography, cardiac MRI and various blood tests. The blood markers most often used were the creatine kinase-MB (CK-MB) fraction and the troponin levels". All participants were checked using the above guidelines and were diagnosed by a hospital cardiologist consultant (Prakash, 2014).

Cases were eligible, if they met the following criteria: being admitted in the above mentioned hospital, diagnosed with ST or non-ST elevation MI by one of cardiologist; age of at least 50 (Note 1) and 55 years for men and women. The criteria for controls were as follows: the same diagnosis method as used for cases, patients who were 51 and above for men and 56 years of age or older for women, admitted in the same hospital and without history of CVD under 50 and 55 for men and women (Sesso et al., 2001).

\subsection{Procedures}

Data collection was collected by two trained nurses through face to face interviews. The standardized questionnaire was the primary tool for the data collection. As the majority of participants were staying in the hospital for a few days at least, they were requested to answer the questions based on their circumstances before admission to the hospital.

We used the Global Physical Activity Questionnaire (GPAQ, 2004) as a baseline assessment tool to evaluate the level of physical activity. The "Kessler Inventory Test of Distress" (Kessler, 1992) and "The Questionnaire of SES in Tehran" were applied to measure the level of distress and SES (Garmaroudi \& Moradi, 2010). We assessed dietary factors through the "Dietary Pattern Assessment Questionnaire" of the health ministry of Iran. Based on the self-reports of subjects, the analysis for personal and the family history of following diseases: hypertension, diabetes, hyperlipidaemia and CVD were done. Since the duration of hypertension and hyperglycaemia have direct association with age, as we might expect, these risk factors were less common among cases only because of their younger age. Therefore, we excluded these potential risk factors from our analysis.

To assess smoking and opium consumptions direct questions were used. Current smoker was defined as a person who has smoked at least one cigarette per day within the last two months. Ex-smokers were determined as individuals who had stopped smoking for more than a year. Opium addicted was defined as individuals who have 
used opium continually during the last 30 days. Anthropometry measurement was determined by the standard protocol. In addition, the interviewers were carrying out the reviewing of hospital records of participants; all biochemical markers data was collected through the hospital records. The highest level of CK-MB and Troponin were saved; and for other biochemical markers, only tests within 24 hours of admission were finally used for the analysis (Xiaobi, Jianzhang, \& Hengshan, 2006).

\subsection{Ethical Consideration}

For the ethical issues, we followed the Shahid Rajaie Hospital instructions. We attached a permission letter and a cover letter at the end of questionnaires. Before starting the interview the participants were asked to sign the cover letter. All data gathered from the questionnaires, including the respondents' personal information and answers, was stored safely and was not accessible to anyone apart from the supervisor and the project manager.

\subsection{Data Analysis}

The profile of risk factors in cases and controls was assessed using Chi square and t-tests; and crude and adjusted odds ratio and their $95 \%$ confidence intervals were computed using logistic regression models. Statistical analysis was performed by STATA version 11 SE (Stata Corp LP Texas, USA).

\section{Results}

From all 388 subjects, $81.1 \%$ (315) were male and their mean ages were (44.2) and (63.3) years among cases and controls. Table 1 shows that the prevalence of the following risk-factors was higher in cases: mild \& severe distress $(54.9 \%$ vs $30.5 \%)$, current smoker $(41.0 \%$ vs $29.3 \%)$, low physical activity $(53.2 \%$ vs. $36.4 \%)$ and minorities in comparison to Fars race (65.5\% vs $48.4 \%)$.

Table 1. Comparison of characteristics between cases and controls

\begin{tabular}{llll}
\hline Variables & Case & Control & \\
\hline Indicators & $\mathrm{n}=122(\%)$ & $\mathrm{n}=266(\%)$ & p-value \\
\hline Distress & & & \\
Low\& Mild & $55(45.1)$ & $185(69.5)$ & (based) \\
Moderate \& Severe & $67(54.9)$ & $81(30.5)$ & $<0.01$ \\
Marital status & & & \\
Single & $6(4.9)$ & $18(6.7)$ & (based) \\
Married & $112(91.8)$ & $243(91.3)$ & 0.5 \\
Regular Opium use & & & \\
No & $102(83.6)$ & $225(87.9)$ & (based) \\
Yes & $20(16.4)$ & $31 \quad(12.1)$ & 0.25 \\
Smoking & & & \\
Non-smoker & $62(38.5)$ & $123(40.4)$ & (based) \\
Ex-smoker & $25(20.5)$ & $78(29.3)$ & 0.04 \\
Current smoker & $50(41)$ & $78(29.3)$ & 0.04 \\
History of hypertension & & & \\
Without & $97(79.5)$ & $171(64.3)$ & (based) \\
$5<$ years & $10(8.20)$ & $45(16.9)$ & 0.01 \\
$5 \geq$ years & $15(12.3)$ & $50(18.8)$ & 0.05 \\
History of diabetes & & & \\
Without & $95(77.8)$ & $186(69.9)$ & (based) \\
$5<$ years & $11(9.0)$ & $27(10.1)$ & 0.55 \\
$5 \geq$ years & $16(13.1)$ & $53(19.9)$ & 0.09 \\
& & & \\
\hline
\end{tabular}




\begin{tabular}{llll}
\hline History of hyperlipidaemia & & & \\
Without & $89(72.9)$ & $201(75.5)$ & (based) \\
$5<$ years & $18(14.7)$ & $31(11.6)$ & 0.4 \\
$5 \geq$ years & $15(12.3)$ & $34(12.7)$ & 0.99 \\
Physical activity & & & \\
Acceptable & $65(53.2)$ & $97(36.4)$ & (based) \\
Low & $57(46.7)$ & $162(60.9)$ & $<0.01$ \\
Ethnicity background & & & \\
Fars & $42(34.4)$ & $137(51.5)$ & (based) \\
Minorities & $80(65.5)$ & $129(48.4)$ & $<0.01$ \\
\hline
\end{tabular}

Table 2 shows that distress $(\mathrm{OR}=3.95)$, higher education $(\mathrm{OR}=1.30)$, minorities (compared to Fars race) $(\mathrm{OR}=$ 3.30) and family history of hyperlipidaemia $(\mathrm{OR}=1.89)$ significantly increases the risk of premature $\mathrm{MI}$ in the multivariate model. Before multivariate adjustment family history of hypertension $(\mathrm{OR}=1.35)$, current smoking versus no smoking $(\mathrm{OR}=1.60)$, raised cholesterol $(\mathrm{OR}=1.11)$, raised $\mathrm{LDL}(\mathrm{OR}=1.12)$, raised Triglyceride $(\mathrm{OR}=1.05)$, raised VLDL $(\mathrm{OR}=1.40)$, consuming fast-food $(\mathrm{OR}=1.48)$ and non-alcoholic beverages $(\mathrm{OR}=1.12)$ also had risk factors but the effects were diminished considerably after adjustments of other variables.

Table 2. Risk factors of premature myocardial infarction

\begin{tabular}{|c|c|c|c|}
\hline \multirow{2}{*}{$\begin{array}{l}\text { Variables } \\
\text { Minorities (compared to Fars race) }\end{array}$} & \multicolumn{2}{|c|}{ Crude OR $[95 \% \mathrm{CI}]$} & Adjusted OR $[95 \% \mathrm{CI}]$ \\
\hline & 2.02 & {$[1.30-3.15] \dagger$} & $3.30 \quad[1.51-7.21] \dagger$ \\
\hline Moderate and severe distress & 2.78 & {$[1.79-4.33] \dagger$} & {$[1.93-8.08] \dagger$} \\
\hline Higher education & 1.19 & {$[1.07-1.32] \dagger$} & {$[1.09-1.56]$} \\
\hline \multicolumn{4}{|l|}{ Smoking: } \\
\hline Ex-smoker & 0.58 & {$[0.35-0.98] \dagger$} & {$[0.12-0.61] \dagger$} \\
\hline Current smoker & 1.60 & {$[1.02-2.51] \dagger$} & {$[0.41-1.94]$} \\
\hline Family history of hyperlipidaemia & 1.79 & {$[1.21-2.64] \dagger$} & {$[1.01-3.54] \dagger$} \\
\hline Family history of hypertension & 1.35 & {$[1.05-1.74] \dagger$} & {$[0.86-2.00]$} \\
\hline Consuming fast-food & 1.48 & {$[1.17-1.87] \dagger$} & {$[0.89-1.81]$} \\
\hline Consuming non-alcoholic beverages & 1.12 & {$[1.03-1.22] \dagger$} & {$[0.79-1.07]$} \\
\hline Raised Cholesterol & 1.11 & {$[1.05-1.18] \dagger$} & {$[0.87-1.31]$} \\
\hline Raised Triglyceride & 1.05 & {$[1.02-1.09] \dagger$} & {$[0.28-2.96]$} \\
\hline Raised VLDL & 1.40 & {$[1.13-1.72] \dagger$} & $2.22 \quad[0.00-4523.12]$ \\
\hline Raised LDL & 1.12 & {$[1.05-1.19] \dagger$} & {$[0.79-1.28]$} \\
\hline Family history of diabetes & 1.23 & {$[0.95-1.59]$} & \\
\hline Family history of CVD & 1.22 & {$[0.97-1.54]$} & \\
\hline History of hyperlipidaemia & 1.04 & {$[0.77-1.42]$} & \\
\hline Body Mass Index (BMI) & 1.17 & {$[0.88-1.55]$} & ---- \\
\hline Socio-economic Status (SES) & 1.21 & {$[0.83-1.76]$} & ---- \\
\hline Married & 0.72 & {$[0.28-1.87]$} & ----- \\
\hline Regular Opium use & 1.42 & {$[0.77-2.62]$} & ------ \\
\hline Raised HDL & 1.25 & {$[0.89-1.75]$} & ---------------------- \\
\hline Raised CK-MB & 1.00 & {$[0.98-1.02]$} & --------------------- \\
\hline
\end{tabular}




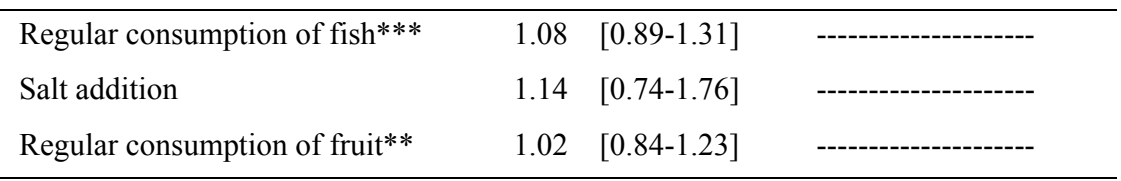

Note. $\uparrow$ Statistically significant as $\mathrm{P}<0.05 ; * *$ Serving per day; $* * *$ Serving per week.

Results also suggest that the regular physical activity $(\mathrm{OR}=0.42)$, ex-smoker compared to a current smoker $(\mathrm{OR}=0.27)$ was protective against premature MI. Regular consumption of milk $(\mathrm{OR}=0.73)$ also significantly decreased the risk of premature MI but only in the crude model (Table 3).

Table 3. Protective factors against premature myocardial infarction

\begin{tabular}{lll}
\hline Variables & Crude OR [95\% CI] & Adjusted OR [95\% CI] \\
\hline Regular physical activity & $0.52[0.34-0.81] \dagger$ & $0.42[0.20-0.86] \dagger$ \\
\hline Ex-smoker versus current smoking & $0.58[0.35-0.98] \dagger$ & $0.27[0.12-0.61] \dagger$ \\
Regular consumption of milk** ${ }^{*} \dagger$ & $0.69[0.43-1.12]$ \\
Raised Troponin & $0.73[0.54-0.99] \dagger$ & --------------- \\
Raised Glucose FBS & $0.85[0.63-1.14]$ & ---------- \\
Regular consumption of vegetables** & $0.98[0.94-1.02]$ & ----------- \\
Note. $\dagger$ Statistically significant as $\mathrm{P}<.05 ; * *$ Serving per day.
\end{tabular}

\section{Discussion}

The major findings of this study are the differences of CVD risk factors in different age groups.

Our study showed that the effect of potential risk factors (distress, smoking, physical inactivity, and dietary patterns) were the main risk factors of premature myocardial infarction. Also family history of hypertension and minorities significantly increased the risk of premature MI.

In accordance with similar research studies, the findings of this study showed distress to be significantly associated with premature MI; since both cases and controls had suffered from MI, stressful life style not only increases the risk of CVD, but also decrease the age of onset. Similar studies have implied that MI is significantly associated with psychological distress (Ferketich \& Binkley, 2005). The results of the INTERHEART project have indicated that prevalence of depression was highest amongst cases in different geographical zones. They also found out that sufferers of depression within the young population category are more at the risk of MI in comparison to those older age groups (Yusuf et al., 2004). Although the full impact of mental stress on heart disease is beginning to become clearer, the underlying mechanisms remain unclear to an extent (Steptoe \& Kivimäki, 2012).

Smoking appears to increase the risk of premature MI. A decreased risk of premature MI was seen among individuals who quit smoking. Yusuf et al. (2004) demonstrated that smoking was more harmful for the younger population, as the increasing risk of MI was higher; additionally, younger individuals have more benefits of reducing the risk of MI after stopping smoking, in comparson to older age groups.

Chow et al. (2010) suggested that patients who continued to smoke without monitoring their diet and any physical activity were 3.8 times more at risk of MI, stroke or death within six months than non-smokers who had changed their diet and increased physical activity (Ferketich \& Binkley, 2005). The results of similar studies that have been conducted in Iran, also showed that smoking is one of the main risk factors for premature MI (Steptoe \& Kivimäki, 2012).

We found out that physical activity can be protective against premature MI. Physiological studies have shown that physical activity can raise blood circulation, which prevents arthrosclerosis; additionally regular exercise is associated with the level of high-density lipoprotein cholesterol (HDLC) and the level of HDL in the blood stream (Harpal, Li, \& Ravi, 2005). However, in contrast to our findings, INTERHEART's study has shown that pysical activity is not asociated with MI in both men and women (Yusuf et al., 2004).

Based on our findings, regular consumption of milk has a protective effect on premature MI. Vegetable intake 
also decreases the risk of premature MI but not by a signficant amount. On the other hand, consuming fast-food and drinking beverages seem to be a potentional risk-factor of premature MI. Similar studies have found that low fruit and vegetable intake may also be a potential risk-factor of premature MI (Harpal et al., 2005).

It would appear as though minorities (compared to Fars) are at greater risk of premature MI, whereas the Fars ethnicity have less frequent cases of premature MI. The reason for this is not necessarily directly addressed by the findings of this study, although it would appear as though different lifestyles, socio-economic status and access to health services in addition to genetic factors may explain this association. Nevertheless, further research with a focus on the role of ethnicity is recommended.

Family history of hypertension and hyperlipidaemia were significantly associated with the increased risk of premature MI. Generally, individuals, whose first-degree family members have suffered from CVD, are more likely to be affected by premature MI (Graham et al., 2007). In accordance with our findings, the results of the studies conducted by Yusuf et al. (2004) and Joshi et al. (2007) have also revealed that family history of CVD increases the risk of premature MI. Furthermore, another study also suggests that family history of CVD augments the risk of premature MI (Rosengren et al., 2010).

Although it could be argued that our findings were, to an extent, cutting edge and contradictory to the opinions of esteemed scientists, limitations caused by the sample size and lack of assessment of moleclular markers have prevented us from being able to evaluate different hypothesis based on the primary data gathered. Additional research would therefore be highly recommended as all cases and controls in this study had suffered from MI. In order to fully cover all aspects of potential risk-factors, we would highly recommend the inclusion of an extra healthy control group in any future studies.

\section{Conclusion}

In light of our findings, modifiable risk factors for premature MI were related to distress and cigarette smoking.

The study also identified family history of hypertension, family history of hyperlipidaemia and minorities (compared to Fars) to be potential risk factors, although further investigation is required in order to understand fully the effects of genetics and environmental factors. Additionally, it was identified that physical activity played a crucial role in decreasing the risk of MI among young age groups, as did the decision to quit smoking. Therefore, the interventions to postpone the occurrence of MI have to be tailored based on modifications to any given persons' lifestyle and behaviour.

\section{Acknowledgments}

Special thanks to Atefeh Vadikheyl and Maryam Mohamdi for their support and cooperation.

\section{Conflict of Interest}

The authors declare that there is no conflict of interests regarding the publication of this paper.

\section{References}

Andrés, E., León, M., Cordero, A., Magallón Botaya, R., Magán, P., \& Luengo E. (2011). Cardiovascular Risk Factors and Lifestyle Associated With Premature Myocardial Infarction Diagnosis. Rev Esp Cardiol, 64(6), 527-529. http://dx.doi.org/10.1016/j.recesp.2010.09.012

Avies, R. W., Wells, G. A., Stewart, A. F., Erdmann, J., Shah, S. H., \& Ferguson, J. F. (2012). A genome wide association study for coronary artery disease identifies a novel susceptibility locus in the major histocompatibility complex. Circ Cardiovasc Genet, http://dx.doi.org/10.1161/CIRCGENETICS.111.961243

Azizi, F., Janghorbani, M., \& Hatami, M. (2000). Epidemiology and Control of Common Disorders in Iran (3rd ed.). Tehran: Jeyhoon. [in Persian]

Buttar, B S., Li, T., \& Ravi, N. (2005). Prevention of cardiovascular diseases: Role of exercise, dietary interventions, obesity and smoking cessation. Exprimental and Clinical Cardiology, 10(4), 229-249.

Chow, C. K., Jolly, S., Rao-Melacini, P., Fox, K. A., Anand, S. S., \& Yusuf, S. (2010). Association of Diet, Exercise, and Smoking Modification With Risk of Early Cardiovascular Events After Acute Coronary Syndromes. Circulation, 121(6), 750. http://dx.doi.org/10.1161/CIRCULATIONAHA.109.891523

Ferketich, A. K., \& Binkley, P. F. (2005). Psychological distress and cardiovascular disease: results from the 2002 National Health Interview Survey. European Heart Journal, 26(18), 1923-1929. http://dx.doi.org/10.1093/eurheartj/ehi329 
Fuster, V., \& Kelly, B. B. (2010). Promoting Cardiovascular Health in the Developing World: A Critical Challenge to Achieve Global Health. Institute of Medicine (US) Committee on Preventing the Global Epidemic of Cardiovascular Disease, Washington (DC). Retrieved January 10, 2012, from http://www.ncbi.nlm.nih.gov/books/NBK45688/

Garmaroudi, G. R., \& Moradi, A. (2010). Socio-economic status in Iran: a study of measurement index. Payesh, 9, 137-144.

GPAQ. (2004). GPAQ: General Practice Assessment Questionnaire. Retrieved from World Health Organisation: http://www.who.int/chp/steps/GPAQ/en/

Graham, I., Atar, D., Borch-Johnsen, K., Boysen, G., Burell, G., Cifkova, R., et al. (2007). European guidelines on cardiovascular disease prevention in clinical practice: Executive summary: Fourth Joint Task Force of the European Society of Cardiology and Other Societies on Cardiovascular Disease Prevention in Clinical Practice. European Journal of Cardiovascular Prevention \& Rehabilitation, 14(2), 2375-414. http://dx.doi.org/10.1097/01.hjr.0000277984.31558.c4

Joshi, P., Islam, S., Pais, P., Reddy, S., Dorairaj, P., Kazmi, K., ...Yusuf, S. (2007). Risk Factors for Early Myocardial Infarction in South Asians Compared With Individuals in Other Countries. JAMA, 207(3). http://dx.doi.org/10.1001/jama.297.3.286

Kazemi, T., Sharifzadeh, G., Zarban, A., Fesharakinia, A., Rezvani, R., \& Moezy, A. (2011). Risk Factors for Premature Myocardial Infarction: A Matched Case-Control Study. Journal of Research in Health Sciences, 11(2), 673-676.

Kessler. (1992). The Kessler 10-Information for health professionals. Retrieved from http://www.health.vic.gov.au/healthstatus/downloads/vic_health_survey_07_findings_part_c.pdf

Meysamie, A., Ghaletaki, R., Haghazali, M., Asgari, F., Rashidi, A., \& Khalilzadeh, O. (2010). Pattern of tobacco use among the Iranian adult population: results of the national Survey of Risk Factors of Non-Communicable Diseases (SuRFNCD-2007) Tob Control. Tob Control, 19(2). http://dx.doi.org/10.1136/tc.2009.030759

Prakash, B. (2014). Nuclear Medicine: A Guide for Healthcare Professionals and Patients. Springer India. http://dx.doi.org/10.1007/978-81-322-1826-5

Rosengren, A., Hawken, S., Ôunpuu, S., Sliwa, K, Zubaid, M., Almahmeed, W. A., \& Blackett, K. (2010). Risk factors for Early Myocardial Infarction in South Asians compared with individuals in other countries. JAMA, 297(286-94).

Sesso, H. D., Lee, I. M., Gaziano, J. M., Rexrode, K. M., Glynn, R. J., \& Buring, J. E. (2001). Maternal and Paternal History of Myocardial Infarction and Risk of Cardiovascular Disease in Men and Women. Circulation, 104(4). http://dx.doi.org/10.1161/hc2901.093115

Sezavar, H., Amini Sani, N., \& Alavizadeh, S. A. (2004). Cardiac risk factor in young adult: A case control study. Journal of Ardabil University of Medical Sciences, 4(13), $51-56$ [In Persian].

Shojaie, M., Pourahmad, M., Eshraghian, A., \& Izadi, H. (2009). Fibrinogen as a risk factor for premature myocardial infarction in Iranian patients: A case control study. Vasc Health Risk Manag, 5, 673-676. http://dx.doi.org/10.2147/VHRM.S6559

Steptoe, A., \& Kivimäki, M. (2012). Stress and cardiovascular disease. Nature Reviews Cardiology, 9(6). http://dx.doi.org/10.1038/nrcardio.2012.45

WHO. ( 2004 ). Retrieved October 22, 2011, from WHO: http://www.who.int/chp/steps/GPAQ/en/

WHO. (2002). Reducing risks, promoting healthy life. Retrieved from World Health Organisation: http://www.who.int/whr/2002/en/whr02_en.pdf?ua=1

Xiaobi, G., Jianzhang, F., \& Hengshan, G. (2006). The predictive value of the bedside troponin T test for patients with acute chest pain. Experimental \& Clinical Cardiology, 11(4), 298-301.

Yusuf, S., Hawken, S., Ounpuu, S., Dans, T., Avezum, A., Lanas, F., \& Lisheng, L. (2004). Effect of potentially modifiable risk factors associated with myocardial infarction in 52 countries (the INTERHEART study): case-control study. The Lancet, 364, 937-952. http://dx.doi.org/10.1016/S0140-6736(04)17018-9 


\section{Note}

Note 1. After we reviewed several articles, we had realized that age 50 for men and 55 for women would get the best accuracy for the cutoff point. (Graham I. et al., 2007).

\section{Copyrights}

Copyright for this article is retained by the author(s), with first publication rights granted to the journal.

This is an open-access article distributed under the terms and conditions of the Creative Commons Attribution license (http://creativecommons.org/licenses/by/3.0/). 